\title{
Retraction notice for: "Ginsenoside Rg1 protects human renal tubular epithelial cells from lipopolysaccharide-induced apoptosis and inflammation damage" [Braz J Med Biol Res (2018) 51(2): e6611]
}

X.J. Ni, Z.Q. Xu, H. Jin, S.L. Zheng, Y. Cai, and J.J. Wang Transplantation Center, The First Affiliated Hospital of Wenzhou Medical University, Wenzhou, China

Retraction: Braz J Med Biol Res | doi: 10.1590/1414-431X20176611 | PMID: 29267498 | PMCID: PMC5731327

The Editors of the Brazilian Journal of Medical and Biological Research (BJMBR) became aware of a denouncement published by independent journalists from the "For Better Science" website including this paper. This denouncement consisted of potential data falsification and/or inaccuracy of results in western blots and flow cytometry plots.

After contacting the Authors and per consensus between the Editors-in-Chief of the BJMBR and the Authors, this article has been retracted. 


\title{
Ginsenoside Rg1 protects human renal tubular epithelial cells from lipopolysaccharide-ind cond apoptosis and inflammation dam, $\mathrm{O}$.
}

\author{
X.J. Ni, Z.Q. Xu, H. Jin, S.L. Zheng, Y. ar and J. Wang \\ Transplantation Center, The First Affiliated Hospital of Wenzhou Medic-l Un rsity, V nzhou, China
}

\begin{abstract}
Ginsenoside Rg1, one of the most notable active components of Panax ginsenc been v. ely reported to exert antiinflammatory actions. This study aimed to reveal whether ginsenoside $\mathrm{Rg} 1$ so hibits beneficial roles against lipopolysaccharide (LPS)-induced apoptosis and inflammation in human renal cells, and to evaluate the potential role of the component on tubulointerstitial nephritis treatment. HK-2 were treated with various doses of ginsenoside $\operatorname{Rg} 1(0,50,100,150$, and $200 \mu \mathrm{M})$ in the absence or prese $f 5 \mu \mathrm{g} / \mathrm{h}$ LPS. Thereafter, CCK-8 assay, flow cytometry, western blot, migration assay, reactive oxygen species (ROS) say CLISA were carried out to respectively assess cell viability, apoptosis, migration, ROS activity, and the release of mmatory cytokines. As a result, ginsenoside Rg1 protected HK-2 cells from LPS-induced injury, as cell viability was inc ised, cell apoptosis was decreased, and the release of MCP-1, IL-1 $\beta$, IL-6, and TNF- $\alpha$ was reduced. Gins ide Rg1 hunctioned to HK-2 cells in a dose-dependent manner, and the $150 \mu \mathrm{M}$ dose exhibited the most protective anctic Ginsenoside Rg1 had no significant impact on cell migration and ROS activity, while it alleviated LPS-induced S relea and migration impairment. Furthermore, the downregulations of $\mathrm{p}-\mathrm{PI} 3 \mathrm{~K}, \mathrm{p}-\mathrm{AKT}$, and up-regulations of PT $\mathrm{N}, \mathrm{p}-, \alpha, \gamma, 65, \mathrm{Bcl}-3$ induced by LPS were recovered to some extent after ginsenoside Rg1 treatment. In concl ion jinst, side Rg1 protects HK-2 cells against LPS-induced inflammation and apoptosis via activation of the PI $4 \mathrm{~K}$ path'ay and suppression of NF-KB pathway.
\end{abstract}

Key words: Ginsenoside Rg1; LPS; Apoptosis flammatı /3K/AKT pathway; NF-кB pathway

\section{Introduction}

Ginseng, the root of the widely ginseng, has been used as Chinese ditior medicine for at least 1000 years (1). Cu the it is vire of the most extensively researched and pres ibto native medicines worldwide (1). This drug exerts $p$ acological actions for several diseases incly is liabe s, neurological condition, cardiovascular eas and even cancer (1-4). The molecular compor sn. ponsivie for the beneficial effect of ginseng includ ginseno $\mathrm{s}$, which are triterpene saponins that consist ilu steroid skeleton and sugar moieties. Among the 30 diffe varieties of ginsenosides, $\mathrm{Rg} 1$ is one of th meior pharmacologically active and abundant ingred +1 . Several studies have demonstrated the different b fici- effects of ginsenoside Rg1, which include ? imma and anti-apoptotic effects (1-7). An early viv L.... has reported that intraperitoneal injection with noside $\mathrm{Rg} 1$ in rats resulted in a prevention of urinary prou excretion, an elevation of serum cholesterol content, as well as histopathological changes such as hypercellularity and adhesion (8), indicating the therapeutic potential of ginsenoside Rg1 in nephritis. However, to our knowledge, the detailed functions of ginsenoside $\mathrm{Rg} 1$ on tubulointerstitial nephritis and its underlying molecular mechanisms have not been uncovered.

PI3K/AKT pathway has been shown to play a central role in different biological processes such as angiogenesis, tumorigenesis, and inflammation (3). This pathway is also known to play an important role in inflammation by taking part in cell growth modulation, and maturation of different cellular components of the inflammation pathway (3). Similarly, NF-кB pathway is responsible for modulating multiple cellular processes especially in inflammation and apoptosis (4). Several chronic inflammation diseases like inflammatory bowel disease, sepsis, arthritis, and atherosclerosis have been revealed to be associated with chronic activation of NF-KB $(4,7)$. Recent studies have indicated that ginsenoside $\mathrm{Rg} 1$ is able to activate PI3K/AKT signaling through a glucocorticoid receptor (GR)-dependent manner, 
and it has been shown to be a functional ligand of GR (9). In contrast, ginsenoside Rg1 suppresses the activation of NF-kB pathway also through a GR-dependent manner $(4,10)$. Based on these findings we hypothesize that ginsenoside Rg1 might be a potential anti-inflammatory drug at least in part via modulation of PI3K/AKT and NF-KB pathways.

This study aimed to explore the beneficial role of ginsenosides Rg1 against lipopolysaccharide (LPS)-induced apoptosis and inflammation damage in human renal tubular epithelial cells and also investigate its underlying mechanism. This study will provide in vitro information supporting ginsenoside $\mathrm{Rg} 1$ as a potential anti-inflammatory drug for tubulointerstitial nephritis treatment.

\section{Material and Methods}

\section{Cell culture and treatment}

Human renal tubular epithelial cell line HK-2 was obtained from American Type Culture Collection (ATCC, USA), and was cultured in Dulbecco's Modified Eagle's Medium/Nutrient Mixture F-12 (DMEM-F12, 3:1, Gibco-BRL, USA) supplemented with $10 \%$ fetal bovine serum (FBS, Gibco-BRL) in a humidified $5 \% \mathrm{CO}_{2}$ atmosphere at $37^{\circ} \mathrm{C}$.

Ginsenoside Rg1 with purity greater than $98 \%$ (Nationa' Institutes for Food and Drug Control, China) were dissolved in DMSO (Sigma-Aldrich, USA) and mixed ith the medium so that the final concentration of the hic $^{\prime}$ was less than $0.1 \%$. To analyze the function l In $^{-}$is of ginsenoside $\mathrm{Rg} 1$ following LPS stimulatior cells $\mathrm{m}$ incubated with various doses of ginsenosi $(0,50$, $100,150$, and $200 \mu \mathrm{M})$ in the presence or absence of $\mathrm{q} / \mathrm{mL}$ LPS (from Escherichia coli O111:B4 y.ha-Aldricin) for $24 \mathrm{~h}(11)$.

\section{CCK-8 assay}

The viability of HK-2 cells an nessed by using a Cell Counting Kit-8 (CCK-8, Dojir , recular Technologies, USA). Briefly, cells wer ded a 96-well plate with a density of $5 \times 10^{3} \mathrm{ce}^{\prime}$, we and en cells were treated with ginsenoside Rg nor $24 \mathrm{~h}$. The cells were further incubated ' fres, edium for $48 \mathrm{~h}$, and then $10 \mu \mathrm{L}$ CCK-8 solutic s adde, to the culture medium. The plates were incuba for $30 \mathrm{~min}$ at $37^{\circ} \mathrm{C}$ in humidified $95 \%$ air $45 \% \mathrm{CO}_{2}$. he absorbance was measured at $450 \mathrm{np}$ usin a Microplate Reader (Bio-Rad, USA).

A. sis sis

Tr FITC--_nnexin V/PI detection kit from Beijing Biosea yy Co., Ltd. (China) was utilized in the present wo. for detection of cell apoptosis. In brief, cells were growr .0 about $70 \%$ confluence in 6 -well plates and treated with ginsenoside Rg1 and/or LPS for $24 \mathrm{~h}$, followed by 48-h incubation in fresh medium at $37^{\circ} \mathrm{C}$. Cells $\left(1 \times 10^{5}\right)$ in each sample were then collected and resuspended in $200 \mu \mathrm{L}$ Annexin-Binding Buffer, and stained with $10 \mu \mathrm{L}$ FITC-Annexin $V$ and $5 \mu \mathrm{L} \mathrm{PI}$ for $30 \mathrm{~min}$ in the dark at room temperature. Flow cytometry analysis was done by using a FACS can (Beckman Coulter, USA).

\section{Western blot}

The protein used for western blotting was extrac 'us' $y$ RIPA lysis buffer (Beyotime Biotechnolory, China) su siemented with protease inhibitors (Roche, itzerlar $)$ The proteins were quantified using the $\mathrm{P}$ Pro in ssay Kit (Pierce, USA). The western blot ystem was stablished using a Bio-Rad Bis-Tris Gel tem a ording to the manufacturer's instructions. mal nti' dies were prepared in $5 \%$ blocking buff at a stion of $1: 1,000$. Primary antibody was incubated the me ane at $4^{\circ} \mathrm{C}$ overnight, followed by wash anu incu tion with secondary antibody marked by horsere peroxia for $1 \mathrm{~h}$ at room temperature. After rinsin rne lyvinylidene difluoride (PVDF) membrane carrying "otc tibodies were transferred into the Bio-Rad Che. 'oc ${ }^{\mathrm{TM}}$ XRS system, and then $200 \mu \mathrm{L}$ Immobi! "astern hemiluminescent HRP Substrate (Millipore, SA added to cover the membrane surface. The signals e captured and the intensity of the bands was quantified us Image Lab ${ }^{\text {TM }}$ Software (Bio-Rad, China).

\section{Migr on assay}

Ce migration was determined by using a modified vell chamber with a pore size of $8 \mathrm{~mm}$ (Corning, US.1). For migration assay, cells suspended in $200 \mathrm{~mL}$ of erum-free medium were seeded on the upper compartment of 24-well Transwell culture chamber, and $600 \mathrm{~mL}$ of complete medium containing $10 \mu \mathrm{L}$ mitomycin $\mathrm{C}$ was added to the lower compartment. After $12 \mathrm{~h}$ incubation at $37^{\circ} \mathrm{C}$, cells were fixed with methanol. Non-traversed cells were carefully removed from the upper surface of the filter with a cotton swab. Traversed cells on the lower side of the filter were stained with crystal violet (Sigma-Aldrich) and counted. Relative cell migration was calculated as the number of the treated cells normalized to the number of the control cells adhering to the lower chamber.

\section{Reactive oxygen species (ROS) assay}

ROS was measured by flow cytometry using 2,7-dichlorofluorescein diacetate (DCFH-DA; Nanjing Jiancheng Technology Co., China). The cells were seeded in a 6-well plate, and after treatment and washing twice with phosphate buffer saline (PBS), cells were incubated in serum-free culture medium containing $10 \mu \mathrm{M}$ DCFH-DA for $20 \mathrm{~min}$ at $37^{\circ} \mathrm{C}$ in the dark. Subsequently, the cells were washed with PBS, and a trypsin digestion method was used for sample collection. All samples were centrifuged and the supernatants were removed. The cells were resuspended to $500 \mu \mathrm{L}$ PBS and the fluorescent intensities were measured using a flow cytometer (488 $\mathrm{nm}$ excitation, $521 \mathrm{~nm}$ emission).

\section{Enzyme-linked immunosorbent assay (ELISA)}

Culture supernatant was collected from 24-well plates and concentrations of MCP- $1, \mathrm{IL}-1 \beta, \mathrm{IL}-6$, and TNF- $\alpha$ were 
measured by human CCL2/MCP-1 Quantikine ELISA kit, human IL-1 beta/IL-1F2 Quantikine ELISA kit, human IL-6 Quantikine ELISA kit, and human TNF-alpha Quantikine ELISA kit (all from R\&D Systems, UK), respectively, according to the manufacturer's instructions.

\section{Statistical analysis}

All experiments were done in triplicate. The results of multiple experiments are reported as means \pm SD. Statistical analyses were performed using Graphpad statistical software (GraphPad Software Inc., USA). P values were calculated using one-way analysis of variance (ANOVA). $\mathrm{P}<0.05$ was considered to be statistically significant.

\section{Results}

\section{Ginsenoside Rg1 alleviated LPS-reduced HK-2 cells viability}

HK-2 cells were treated with increasing doses of ginsenoside Rg1 (structure depicted in Figure 1A) in the presence or absence of $5 \mu \mathrm{g} / \mathrm{mL}$ LPS, and then cell viability was measured to evaluate the functional effects of ginsenoside Rg1 on cell viability. At doses of $100 \mu \mathrm{m}(\mathrm{P}<0.05), 150 \mu \mathrm{m}(\mathrm{P}<0.01)$, and $200 \mu \mathrm{m}(\mathrm{P}<0.01)$, ginsenoside $\mathrm{Rg} 1$ caused a s ificant increase in the cell viability compared to control grr $p$ of " $" \mathrm{~K}-2$ cells (Figure 1B). In addition, $5 \mu \mathrm{g} / \mathrm{mL}$ of LPS ap acally reduced cell viability $(P<0.001)$, while $100 \mu \mathrm{m}$ ( 0.0 , $150 \mu \mathrm{m}(\mathrm{P}<0.01)$, and $200 \mu \mathrm{m}(\mathrm{P}<0.01$ ginsenosia $\mathrm{g} 1$ partially alleviated LPS-reduced cell viab. (Figur $1 \mathrm{C}$ ).

\section{Ginsenoside Rg1 alleviated LF -induced h.. -2 cells apoptosis}

Cell apoptosis was als rete rowing various doses of ginsenoside $\mathrm{Ro}$ in th resence or absence of LPS. Flow cytometry df tion resu. showed that $5 \mu \mathrm{g} / \mathrm{mL}$ of LPS induced a S.gnific + increase in apoptotic cell rate $(P<0.001, F$, $2 A)$ doses of ginsenoside Rg1 (100, 150, d 2$) \mu \mathrm{M})$ significantly suppressed LPSinduced apop is $\quad$ or $P<0.001)$. Expression changes of apopu -related factors in cells were detected by west lot ana is, as shown in Figure $2 \mathrm{~B}$ and $\mathrm{C}$. Bax and $\mathrm{f}$ W regulated, Bcl-2 was down-regulated, while casp 3 was cleaved after LPS stimulation (all $\mathrm{P}<0.001$ ). re importantly, 100,150 , and $200 \mu \mathrm{M}$ of

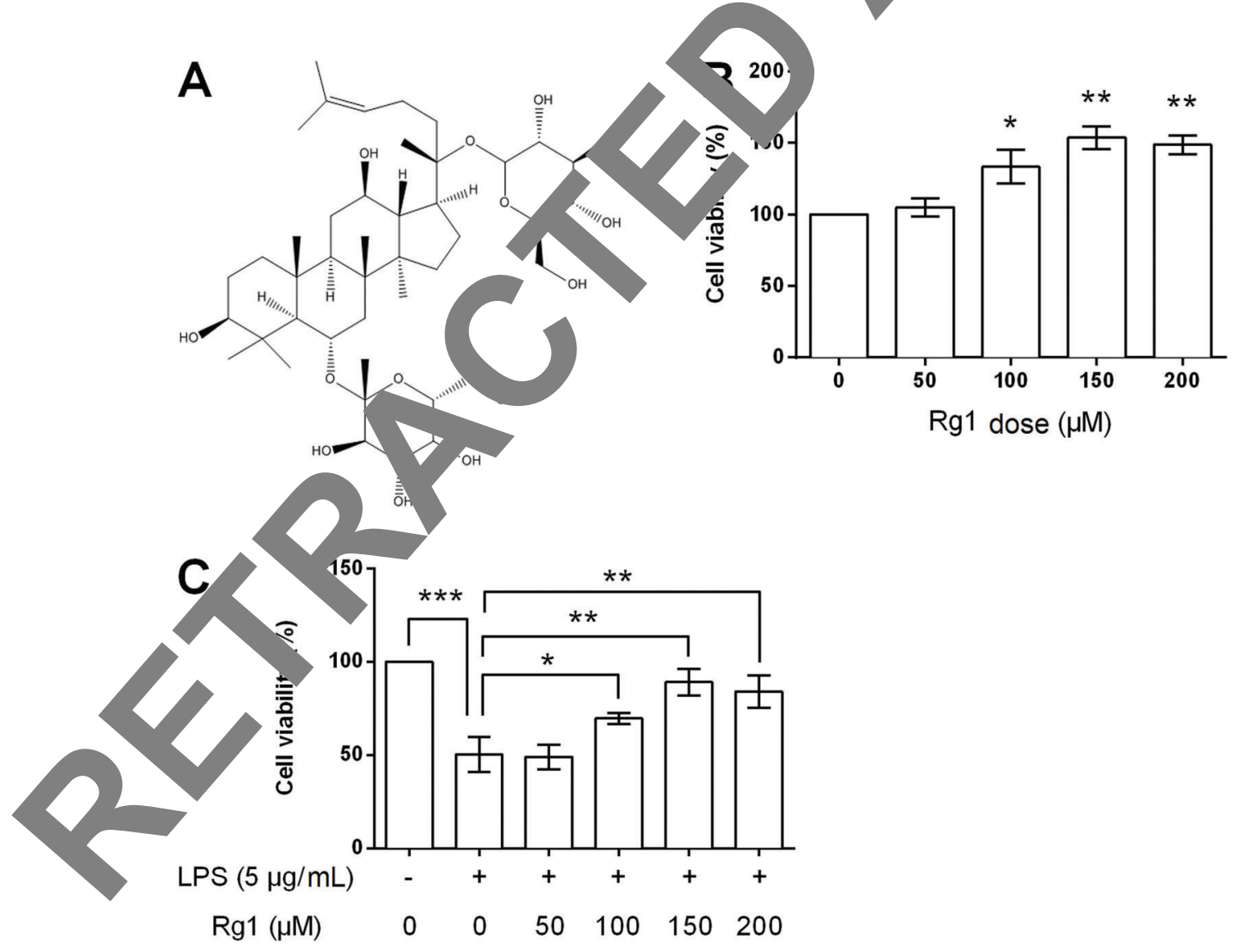

Figure 1. $A$, Structural formula of ginsenoside Rg1. $B$, Viability of HK-2 cells treated with ginsenoside $\operatorname{Rg} 1(0,50,100,150$, and $200 \mu \mathrm{M})$ or pretreated with $5 \mu \mathrm{g} / \mathrm{mL}$ lipopolysaccharide (LPS) $(C)$. Data are reported as means $\pm S D(n=3)$. ${ }^{*} P<0.05,{ }^{* *} P<0.01$, and ${ }^{* * *} P<0.001$ (ANOVA). 
A



B

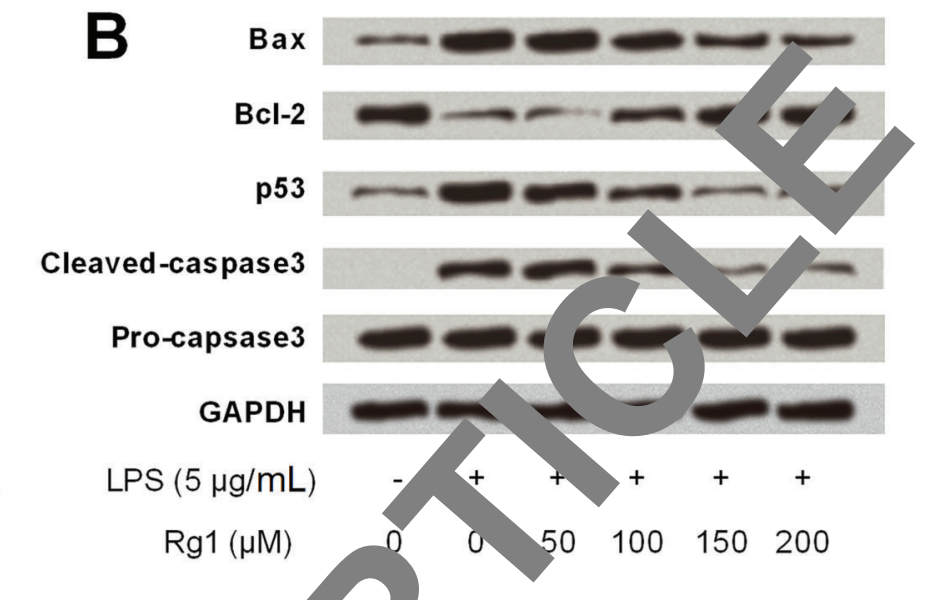

Cleaved-caspase 3

Pro-capsase 3

GAPDH

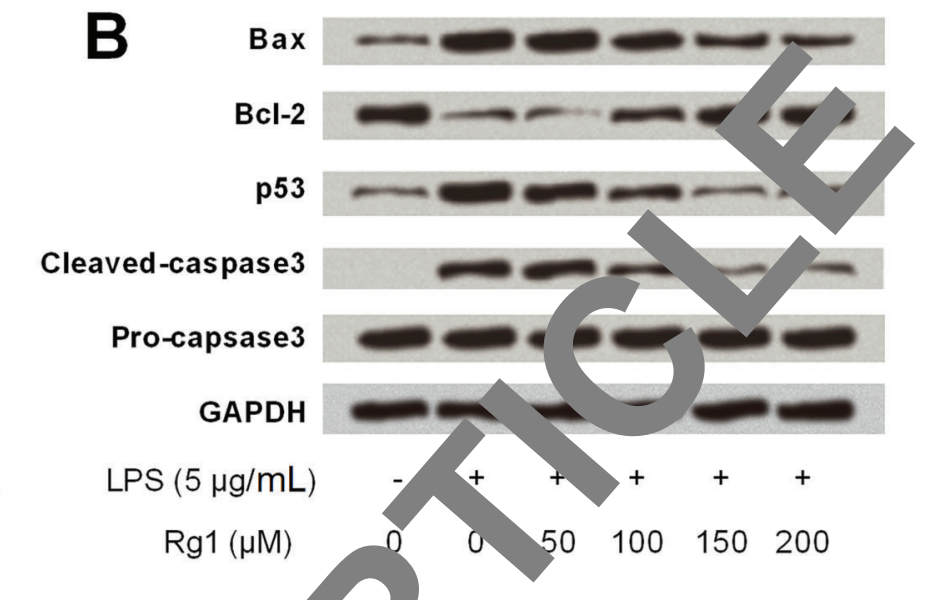

$\operatorname{LPS}(5 \mu \mathrm{g} / \mathrm{mL})$

$\mathrm{Rg} 1(\mu \mathrm{M})$

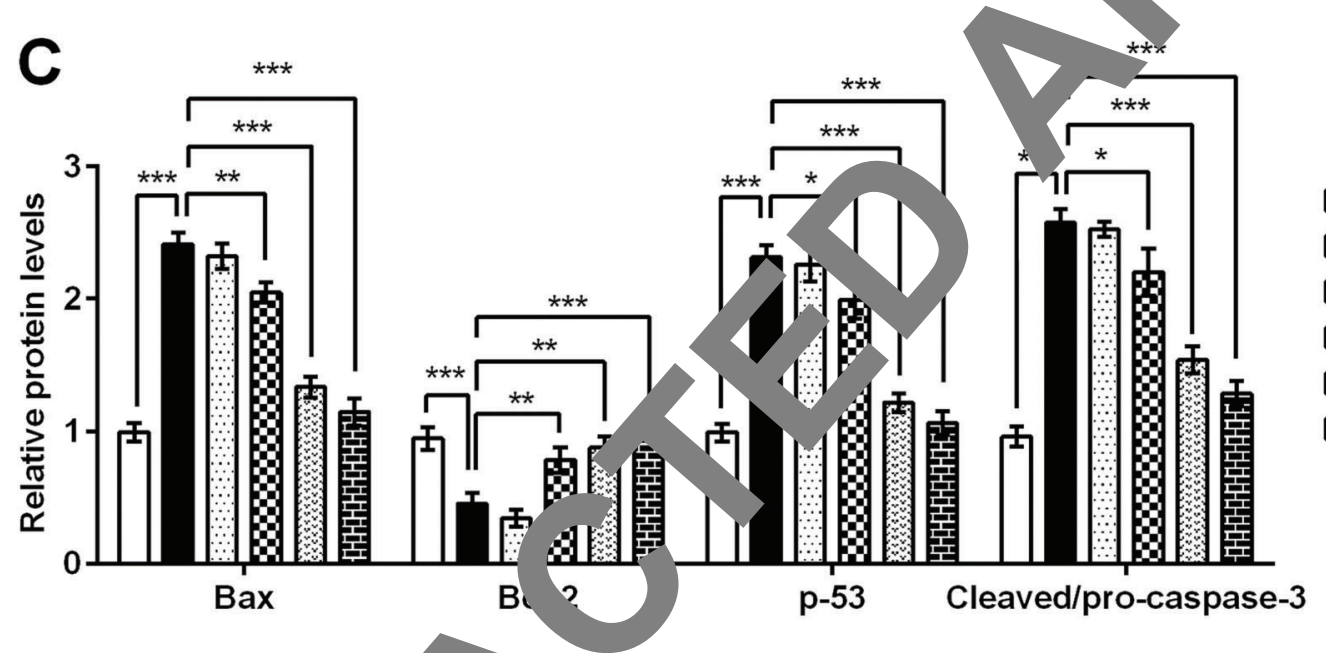

Figure 2. Ginsenoside Rg1 inhibit IIf naccharide (LPS)-induced HK-2 cells apoptosis. HK-2 cells were treated with ginsenoside $\operatorname{Rg} 1(0,50,100,150$, and $200 \mu \mathrm{M}) \mathrm{h}$.osence or presence of $5 \mu \mathrm{g} / \mathrm{mL} \mathrm{LPS}$, and then apoptotic cell rate $(A)$, and protein expression levels of Bax, Bcl-2, p53, ed-co ase3, and pro-caspase3 were assessed ( $B$ and $C$ ). Data are reported as means $\pm S D(n=3)$. ${ }^{*} \mathrm{P}<0.05,{ }^{* *} \mathrm{P}<0.01$, an ${ }^{*} \mathrm{P} \quad 0.001$ NOVA).

ginsenoside $\mathrm{Rg}$ " coula "eviate LPS-induced abnormal expressions of factors $\backslash<0.05, \mathrm{P}<0.01$ or $\mathrm{P}<0.001$ ), and it seemea that regulatory effects of ginsenoside Rg1 might be a dose-dep, dent manner.

\section{Ginsen. Ro alleviated LPS-reduced migration in} H' ells

Tc detect ne role of ginsenoside $\mathrm{Rg} 1$ in the migrar renal tubular epithelial cells, HK-2 cells we. treated with LPS and/or $150 \mu \mathrm{m}$ ginsenoside Rg1, and tr. n cell migration was assessed. LPS significantly reduced the relative migration rate $(P<0.001)$, while ginsenoside Rg1 showed no effect on the migration of HK-2 cells. Moreover, ginsenoside Rg1 at a dose of $150 \mu \mathrm{m}$ significantly $(\mathrm{P}<0.05)$ suppressed LPS-induced decrease in migration of HK-2 cells (Figure 3 ).



Figure 3. Ginsenoside Rg1 alleviated lipopolysaccharide (LPS)induced HK-2 cell migration. HK-2 cells were treated with $150 \mu \mathrm{M}$ of ginsenoside Rg1 and/or $5 \mu \mathrm{g} / \mathrm{mL}$ of LPS, and then relative migration rate was detected. Data are reported as means $\pm S D$ $(n=3)$. ${ }^{*} P<0.05$ (ANOVA). 


\section{Ginsenoside Rg1 decreased LPS-induced ROS}

Given that overproduction of ROS can induce apoptosis through both extrinsic and intrinsic pathways (12),

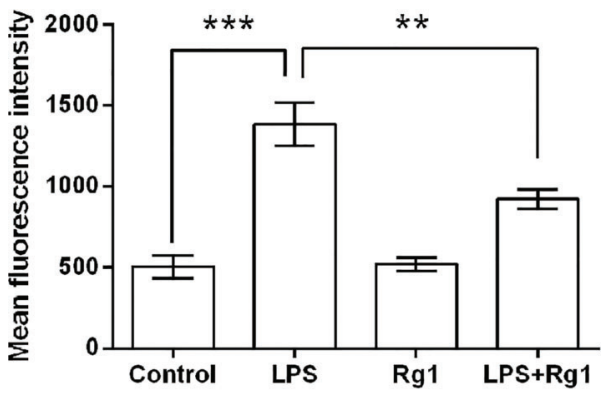

Figure 4. Ginsenoside Rg1 decreased lipopolysaccharide (LPS)induced increase in reactive oxygen species (ROS) activity. HK-2 cells were treated with $150 \mu \mathrm{M}$ of ginsenoside Rg1 and $/ o r 5 \mu \mathrm{g} / \mathrm{mL}$ of LPS, and then ROS activity was detected. Data are reported as means $\pm S D(n=3) .{ }^{* *} P<0.01$ and ${ }^{* *} P<0.001$ (ANOVA). we further detected ROS activity of the HK-2 cells following by treatment with LPS and/or $150 \mu \mathrm{m}$ ginc hoside $\mathrm{Rg} 1$. As mean fluorescence intensity of $\mathrm{RO}$ shr yed in Figure 4, LPS significantly $(P<0.001)$ in $a$ the ROS activity of the HK-2 cells compared to th on cells (HK-2 cells in absence of LPS). Ginsenoside g1 $(150 \mu \mathrm{m})$ had no impact on ROS activity, 'ile it al' yiated the LPS-induced increase of ROS vity, 1 ).

\section{Ginsenoside Rg1 decreased L F-induc d} inflammation response

The concentrations fou nflammatory cytokines, MCP-1, IL-1 $\beta$, IL-6, and' 'F- $\alpha$, in $\perp 2$ cells culture supernatant were detecte fo, ing ginsenoside $\mathrm{Rg} 1$ and LPS treatment. Ac own in ure 5A-D, LPS exposure significantly elf ateo hese four inflammatory cytokines levels in HK- olls supernatants (all $\mathrm{P}<0.001$ ). However, ginsen te Rg1 decreased LPS-induced production hase to $>$ cytokines $(\mathrm{P}<0.05, \mathrm{P}<0.01$ or $\mathrm{P}<0.001, \mathrm{~A}, \mathrm{ose}$ of ginsenoside $\mathrm{Rg} 1$ exhibited a

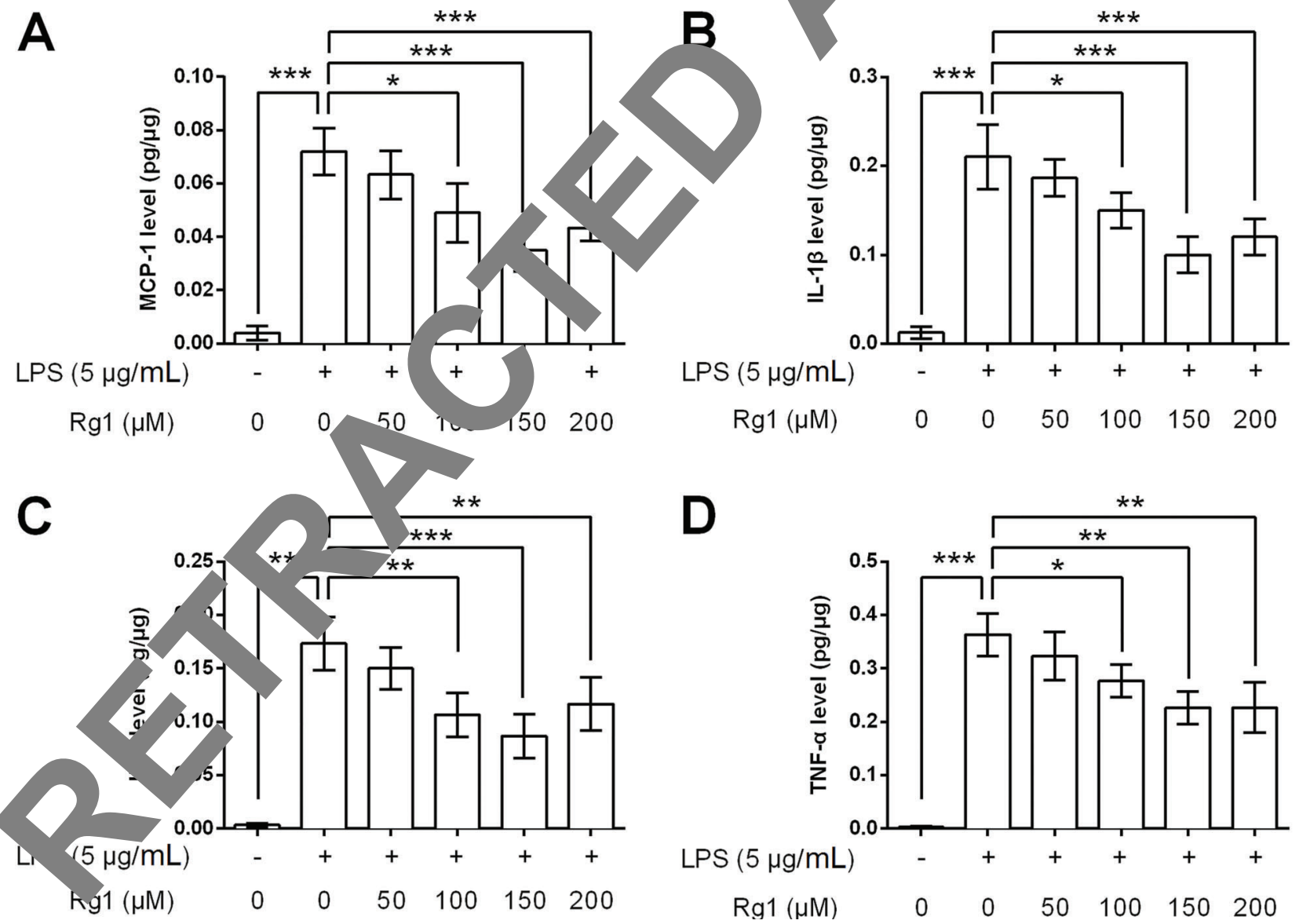

Figure 5. Ginsenoside Rg1 decreased lipopolysaccharide (LPS)-induced inflammation response. HK-2 cells were treated with ginsenoside $\operatorname{Rg} 1(0,50,100,150$, and $200 \mu \mathrm{M})$ in the absence or presence of $5 \mu \mathrm{g} / \mathrm{mL}$ LPS, and then the concentrations of $(A)$ MCP-1, $(B) \mathrm{IL}-1 \beta,(C) \mathrm{IL}-6$, and $(D) \mathrm{TNF}-\alpha$ in culture supernatant were measured. Data are reported as means $\pm \mathrm{SD}(\mathrm{n}=3)$. ${ }^{*} \mathrm{P}<0.05,{ }^{* *} \mathrm{P}<0.01$, and ${ }^{* * *} \mathrm{P}<0.001$ (ANOVA). 
stronger down-regulatory impact on these cytokines, and the maximum decrease in the levels of the abovementioned cytokines of inflammation were seen at a dose of $150 \mu \mathrm{m}$.

\section{Ginsenoside Rg1 suppressed LPS-induced HK-2 cells injury by activation of PI3K/AKT and inactivation of NF- $\kappa B$ signaling pathways}

Further, we focused on PI3K/AKT and NF- $\kappa \mathrm{B}$ signaling pathways to reveal whether they are implicated in ginsenoside Rg1 modulation of HK-2 cells. Western blot analysis showed that $\mathrm{p}-\mathrm{PI} 3 \mathrm{~K}$ and $\mathrm{p}-\mathrm{AKT}$ levels were down-regulated, and PTEN (phosphatase and tensin homolog), $\mathrm{p}-\mathrm{I} \kappa \mathrm{B} \alpha, \mathrm{p}-\mathrm{p} 65$, and $\mathrm{Bcl}-3$ were up-regulated after LPS stimulation (all $P<0.001$, Figure $6 A-D$ ). Meanwhile, ginsenoside $\mathrm{Rg} 1$ recovered these down-regulations and up-regulations $(\mathrm{P}<0.05, \mathrm{P}<0.01$ or $\mathrm{P}<0.001)$, in a dose-dependent manner. No impact was observed in the total levels of PI3K, AKT, I $\mathrm{KB} \alpha$ and p65 after LPS and/or ginsenoside $\mathrm{Rg} 1$ treatment.

\section{Discussion}

Ginsenoside Rg1, the principal component of Chinese medicinal plant Panax, is well-known to possess several beneficial effects (1). Studies have described the pr ective role of ginsenoside Rg1 in diseases associat wit' cardiovascular system, nervous system, using yn ' al cord cells and stem cells (1-7).

The most important beneficial effects g enoside Rg1 include anti-apoptosis and anti-inflammatory tions. $\mathrm{Hu}$ and his colleagues reported the ymsenoside Rg1 protects murine stem cells against $\mathrm{H}_{2}$-indu $d$ apoptosis, as evidenced by the down-re ation cleaved caspase-3 and up-regulation of $\mathrm{Bcl}-2$ arthermore, it has been demonstrated tha im aide $\mathrm{Rg} 1$ protects against $\mathrm{H}_{2} \mathrm{O}_{2}$-induced apoptosis $\rightarrow$ se-uependent mechanism (13). The molecu' o ca inibit the production of LPS-stimulated cytok es (.), anc rotect from ischemia/ reperfusion injury the of inflammation and apoptosis $(14,15$ simin "o these studies, we also found anti-apoptotic anti-in mmatory roles of ginsenoside Rg1 in LrS-St. lated human renal tubular epithelial cells, as $\wedge-2$ cells $v$, vility was increased, the percentage of sop $^{+}$c cell was reduced, and the production of inflamm. cytr ines (MCP-1, IL-1 $\beta, \mathrm{IL}-6$, and TNF- $\alpha$ ) $w$ ollowing treatment with increasing doses gin noside $\mathrm{Rg} 1$ in the presence of LPS.

y accepted that relatively high levels of ROS ca redox imbalance and induce cell apoptosis or necro $s$ in a wide variety of physiological and pathological conditions $(16,17)$. On the other hand, the generation of ROS can be promoted by pro-inflammatory cytokines, such as IL-1 $\beta$ and TNF- $\alpha$, and further deteriorate the inflammation response $(18,19)$. In the current study, we found that ginsenoside $\mathrm{Rg} 1$ had no significant impact on ROS activity, but significantly reduced LPS-induced ROS. This finding further confirmed that ginsenoside Rg1 ex is anti-

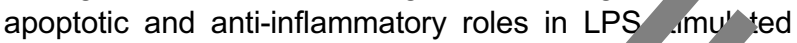
HK-2 cells.

In addition to the importance of cell apopu inflammation, numerous other events such as cell i, sration play pivotal roles in the structure nd fun on of renal tubular epithelial cells $\left(20,2^{1}\right.$ Migra necessary for the renal tubular epitheli cells to acquire normal morphology, cell-cell contact, and nsport pacity $(22,23)$. To date, several studies ginsenoside Rg1 in cell rgra however the mechanism of the interaction controv al. In breast cancer MCF-7 cells, ginseno de treatment suppress phorbol myristate acetate- ' In contrast, in do elial progenitor cells, ginsenoside Rg1 could pr ate gration in a dose- and timedependent mann 24$)$. The discrepancy might be due to the diffe oll type and stress stimuli. In this study, we found tha yins de Rg1 treatment had no impacts on HK-2 cells ration, while it could alleviate LPS-reduced migration, icating a protective role in LPS-induced irment or migration capacity. This fact revealed that ginst side Rg1 improves cell migration not via modulation o pithelial mesenchymal transition (EMT) process, se in that case normal cells (undamaged) treated wit ginsenoside Rg1 would also acquire migration capacity hancement. The exact mechanism of ginsenoside Rg1 effect on human renal tubular epithelial cells migration still needs further investigation.

The PI3K/AKT is an important component of the intracellular signaling pathways tightly linked with cell proliferation, apoptosis, and inflammation response (25-27). NF- $\kappa B$ pathway, a family of transcription factors, is responsible for various biological processes, especially immune and inflammation responses $(28,29)$. More interestingly, $\mathrm{PI3K} / \mathrm{AKT}$ can impact on crosstalk with NF-KB pathway (30), as it is known to regulate the transcriptional activity of $N F-\kappa B$ pathway through phosphorylation and facilitation of $I \kappa B \alpha$ degradation (28). In this study, we explored the protein expressions of main factors in this two signaling pathways and found that PI3K/AKT pathway was activated and NF-кB pathway was suppressed following ginsenoside Rg1 treatment. These data indicated the underlying mechanisms of anti-inflammatory and antiapoptotic actions of ginsenoside Rg1. Our findings are similar to several other studies that reported that ginsenoside Rg1 activates PI3K/AKT signaling (3), and suppresses NF-кB pathway $(4,7,31,32)$.

In conclusion, we suggest that ginsenoside Rg1 plays an important role in the protection of HK-2 cells against LPSinduced inflammation and apoptosis. PI3K/AKT and NF-KB may be two signaling pathways contributing to the protective functions of this molecule on LPS-stimulated HK-2 cells. This study provides information on the therapeutic potential of ginsenoside $\mathrm{Rg} 1$ in tubulointerstitial nephritis. 



$\begin{array}{rrrrrrr}\operatorname{LPS}(5 \mu \mathrm{g} / \mathrm{mL}) & - & + & + & + & + & + \\ \operatorname{Rg} 1(\mu \mathrm{M}) & 0 & 0 & 50 & 100 & 150 & 200\end{array}$


0. Gmsenoside Rg1 suppressed lipopolysaccharide (LPS)-induced HK-2 cells injury by activation of PI3K/AKT and inactivation of $\quad B$ signaling pathways. HK-2 cells were treated with ginsenoside $\operatorname{Rg} 1(0,50,100,150$, and $200 \mu \mathrm{M})$ in the absence or presence of $5 \mu \mathrm{g} / \mathrm{m}$. LPS, and then the protein expressions of p-PI3K, PI3K, p-AKT, AKT, and PTEN, $(A)$, as well as the protein expressions of $\mathrm{p}-\mathrm{I} \mathrm{\kappa} \mathrm{B} \alpha, \mathrm{I} \mathrm{\kappa} \mathrm{B} \alpha, \mathrm{p}-\mathrm{p} 65, \mathrm{p} 65$, and $\mathrm{Bcl}-3(B)$ were determined by western blot analysis. $C$ and $D$, Quantitative analysis based on the results from $A$ and $B$. Data are reported as means $\pm S D(n=3)$. ${ }^{*} P<0.05,{ }^{* *} \mathrm{P}<0.01$, and ${ }^{* * *} \mathrm{P}<0.001$ (ANOVA). 


\section{Acknowledgments}

This study was supported by Science and Technology Department of Wenzhou (No. Y20130199), Zhejiang

\section{References}

1. Sun ZG, Chen LP, Wang FW, Xu CY, Miao G. Protective effects of ginsenoside Rg1 against hydrogen peroxideinduced injury in human neuroblastoma cells. Neural Regen Res 2016; 11: 1159-1164, doi: 10.4103/1673-5374.187057.

2. Zong Y, Ai QL, Zhong LM, Dai JN, Yang P, He Y, et al. Ginsenoside Rg1 attenuates lipopolysaccharide-induced inflammatory responses via the phospholipase C- $\gamma 1$ signaling pathway in murine BV-2 microglial cells. Current Medl Chem 2012; 19: 770-779, doi: 10.2174/0929867127 98992066.

3. Zhang $\mathrm{Y}$, Zhang Z, Wang $\mathrm{H}$, Cai N, Zhou S, Zhao Y, et al. Neuroprotective effect of ginsenoside $\mathrm{Rg} 1$ prevents cognitive impairment induced by isoflurane anesthesia in aged rats via antioxidant, anti-inflammatory and anti-apoptotic effects mediated by the PI3K/AKT/GSK-3 $\beta$ pathway. Mol Med Rep 2016; 14: 2778-2784, doi: 10.3892/mmr.2016.5556.

4. Li LI, Wang Y, Benquan QI, Yuan D, Dong S, Guo D, et al. Suppression of PMA-induced tumor cell invasion and migration by ginsenoside $\mathrm{Rg} 1$ via the inhibition of NF-KBdependent MMP-9 expression. Onco Rep 2014; 32: 1 1786, doi: 10.3892/or.2014.3422.

5. Hu J, Gu Y, Fan W. Rg1 protects rat bone marrow against hydrogen peroxide-induced cell apoptr $s$ th. , th the PI3K/Akt pathway. Mol Med Rep 2016; 14 10.3892/mmr.2016.5238

6. Deng $Y$, Yang $M, X u$ F, Zhang $Q$, Zhan Q, Yu at al. Combined salvianolic acid $B$ and gi riuside Rg1 texerts cardioprotection against ischemia/re rfusion ury in rats. Plos One 2015; 10: e0135435, doi. 0.1371/ irnal.pone. 0135435.

7. Tang YL, Zhou Y, Wang YP, IIN, Ding JC. SIRT6/NF$\kappa B$ signaling axis in ginsenosi $\mathrm{Rg} \quad$ ed hematopoietic stem/progenitor cell senescen nt J Clin Exper Pathol 2015; 8: 5591-5596

8. Hattori T, Ito M, \& Luki IStudit, on antinephritic effects of plant componer. ats a, Effects of ginsenosides on original-type phritis in rats and its mechanisms. Nihon Yak Zasshı 991; 97: 127-134, doi: 10.1254/ fpj.97.2 1.27.

9. Leun W, Pon Wong RN, Wong AS. Ginsenoside$\mathrm{Ro}$ ndur vascular endothelial growth factor expression the gly corticoid receptor-related phosphatidylino-itol as $i \mathrm{kt}$ and beta-catenin/T-cell factor-dependent p iway uman endothelial cells. J Biol Chem 2006; 281: 26288, doi: 10.1074/jbc.M606698200.

Ju J, Cheng B, Zhu X, Ling C. Ginsenoside Rg1, a novel cocorticoid receptor agonist of plant origin, maintains giucocorticoid efficacy with reduced side effects. J Immunol 2011; 187: 942-950, doi: 10.4049/jimmunol.1002579.

11. Li C, Wu J, Li Y, Xing G. Cytoprotective effect of heat shock protein 27 against lipopolysaccharide-induced apoptosis of renal epithelial HK-2 cells. Cell Physiol Biochem 2017; 41: 2211-2220, doi: 10.1159/000475636.
Provincial Natural Science Foundation of China (No. LQ13 H100003), and National Natural Science Foun' cion of China (No. 81501382).

12. Zhang J, Feng Z, Wang C, Zh A, Liu W, Achana K, et al. Curcumin derivative WZ35 fficiently uppresses colon cancer progression through inc ing RO production and ER stress-dependent apop is. . . cer Res 2017; 7: 275-288.

13. Sun ZG, Chen LP. tective $e_{\text {. }}$ ts of ginsenoside Rg1 against hydrogen ,rox induced injury in human neuroblastoma cells. Noural Regu Tes 2016; 11: 1159-1164, doi: 10.4103/167? or 187057.

14. Yang $Y, L i$ Zh? L Liu L, Jing G, Cai H. Ginsenoside Rg1 suppre Intlammnation and neuron apoptosis by activating PPA $\mathrm{nma} / \mathrm{HO}-1$ in hippocampus in rat model of c $2015,2,94$.

15. Xie CL JH, Wang WW, Zheng GQ, Wang LX. Neuroprotectiv ffect of ginsenoside-Rg1 on cerebral ischemia/ reperfusion injury in rats by downregulating protease-activated eptor-1 expression. Life Sci 2015; 121: 145-151, doi: 10.1016/ j.l 2014.12.002.

cu ML, Aw TY. Reactive oxygen species, cellular redox systems, and apoptosis. Free Rad Biol Med 2010; 48: 749, doi: 10.1016/j.freeradbiomed.2009.12.022.

17. Wu D, Luo N, Wang L, Zhao Z, Bu H, Xu G, et al. Hydrogen sulfide ameliorates chronic renal failure in rats by inhibiting apoptosis and inflammation through ROS/MAPK and NF-kappaB signaling pathways. Sci Rep 2017; 7: 455, doi: 10.1038/s41598-017-00557-2.

18. Wu H, Jiang K, Yin N, Ma X, Zhao G, Qiu C, et al. Thymol mitigates lipopolysaccharide-induced endometritis by regulating the TLR4- and ROS-mediated NF-kappaB signaling pathways. Oncotarget 2017; 8: 20042-20055, doi: 10.18632/ oncotarget.15373.

19. Li Q, Engelhardt JF. Interleukin-1beta induction of NFkappaB is partially regulated by $\mathrm{H} 2 \mathrm{O} 2$-mediated activation of NFkappaBinducing kinase. J Biol Chem 2006; 281: 1495-1505, doi: 10.1074/jbc.M511153200.

20. Witzgall R, Brown D, Schwarz C, Bonventre JV. Localization of proliferating cell nuclear antigen, vimentin, c-Fos, and clusterin in the postischemic kidney. Evidence for a heterogenous genetic response among nephron segments, and a large pool of mitotically active and dedifferentiated cells. J Clin Invest 1994; 93: 2175-2188, doi: 10.1172/JCI117214.

21. Bonventre JV. Mechanism of ischemic acute renal failure. Kidney Int 1993; 43: 1160-1178, doi: 10.1038/ki.1993.163.

22. Tian YC, Phillips AO. TGF-beta1-mediated inhibition of HK-2 cell migration. JASN 2003; 14: 631-640, doi: 10.1097/01. ASN.0000053418.56286.5E.

23. Wang W, Reeves WB, Ramesh G. Netrin-1 increases proliferation and migration of renal proximal tubular epithelial cells via the UNC5B receptor. Am J Physiol Renal Physiol 2009; 296: F723-F729, doi: 10.1152/ajprenal.90686.2008.

24. Shi AW, Wang XB, Lu FX, Zhu MM, Kong XQ, Cao KJ. Ginsenoside Rg1 promotes endothelial progenitor cell migration 
and proliferation. Acta Pharmacol Sinica 2009; 30: 299-306, doi: 10.1038/aps.2009.6.

25. Maurya AK, Vinayak M. PI-103 attenuates PI3K-AKT signaling and induces apoptosis in murineT-cell lymphoma. Leuk Lymphoma 2017; 58: 1153-1161, doi: 10.1080/10428194.2016.1225207.

26. Chang YM, Chang HH, Tsai CC, Lin HJ, Ho TJ, Ye CX, et al. Alpinia oxyphylla Miq. fruit extract activates IGFR-PI3K/Akt signaling to induce Schwann cell proliferation and sciatic nerve regeneration. BMC Complement Altern Med 2017; 17: 184, doi: 10.1186/s12906-017-1695-2.

27. Lee IT, Yang CM. Inflammatory signalings involved in airway and pulmonary diseases. Mediators Inflamm 2013; 2013: 791231, doi: 10.1155/2013/791231.

28. Zha L, Chen J, Sun S, Mao L, Chu X, Deng H, et al. Soyasaponins can blunt inflammation by inhibiting the reactive oxygen species-mediated activation of PI3K/Akt/NF-kB pathway. Plos One 2014; 9: e107655, doi: 10.1371/journal. pone.0107655.
29. Nakajima S, Kitamura M. Bidirectional regulation of NFkappaB by reactive oxygen species: a role of tholded protein response. Free Radic Biol Med 2013; $6^{r}$ 162-174, doi: 10.1016/j.freeradbiomed.2013.06.020.

30. Zhang B, Shen Q, Chen Y, Pan R, Kuang S, Myricitrin alleviates oxidative stress-induced inflar on and apoptosis and protects mice age t diabetic cardiomyopathy. Sci Rep 2017; 7: 44239, a 10.1 8/srep 44239.

31. Liu Q, Kou JP, Yu BY. Ginser side $\mathrm{Rg}^{1}$ protects against hydrogen peroxide-induced $c \in$ death il PC12 cells via inhibiting NF-kB activation. roc. In 11 ; 58: 119-125, doi: 10.1016/j.neuint.20

32. Gao Y, Chu S, Li i J, Zha Z, Xia C, et al. Antiinflammatory func $n$ qinsenoside $\mathrm{Rg} 1$ on alcoholic hepatitis through alucocortic receptor related nuclear factorkappa B patt ay. Ethnopharmacol 2015; 173: 231-240, doi: $10.10^{1}$.jep 11507.020 .



